\title{
ORIGINAL ARTICLE \\ Adaptation and validation of the spanish version of the Spinal Cord Lesion-related Coping Strategies Questionnaire (SCL CSQ-S)
}

\author{
J Saurí ${ }^{1,2,3}$, MC Umaña ${ }^{2,4}$, A Chamarro ${ }^{2,5}$, MD Soler ${ }^{1,2,3}$, A Gilabert ${ }^{1,2,3}$ and ML Elfström ${ }^{6}$
}

\begin{abstract}
Study design: Cross-sectional validation study.
\end{abstract}
Objectives: To adapt the Spinal Cord Lesion-related Coping Strategies Questionnaire into the Spanish language (SCL CSQ-S) and to examine the relationship between coping strategies, global quality of life and psychological adaptation.

Setting: Data were collected through individuals with spinal cord injury ( $\mathrm{SCl}$ ) now living in the community who completed their routine follow-up assessment at the Institute Guttmann in Barcelona, Spain.

Methods: Forward and backward translation into Spanish of the English version of the questionnaire. Questionnaires of global Quality of Life, Community Integration, Coping, Depression, Anxiety and Functional Independence were administered to 349 adults with paraplegia and 162 adults with tetraplegia. Statistical analysis included confirmatory factor analysis and regression analysis.

Results: The factorial structure of the questionnaire was partly verified. The original correlated, three-factor model sufficiently fit the data obtained in this study: $\chi^{2}(48)=109.46 ; P<0.001$; Comparative Fit Index $=0.96$; Tucker-Lewis Index $=0.96$; Root Mean Square Error of Approximation $=0.050(0.038-0.062)$; Akaike information criterion $=13.46$. Items were found to be good indicators of their respective latent factors, showing adequate factorial charge ranges (between 0.41 and 0.75 ). The reliability coefficient (Cronbach's $\alpha$ ) for the Acceptance subscale was 0.74 , for Social reliance 0.76 and for Fighting spirit 0.69. Coping strategies as measured by SCL-CSQ-S contributed to the prediction of outcomes related to adaptation to disability.

Conclusion: The results of the study show some evidence for the robustness of the structure of SCL CSQ-S and show that the Spanish version of the questionnaire largely replicate previous results. Coping strategies, especially Acceptance, are related to adaptation to injury.

Spinal Cord (2014) 52, 842-849; doi:10.1038/sc.2014.44; published online 29 April 2014

\section{INTRODUCTION}

Spinal cord injury (SCI) is one of the primary causes of neurological disability in Spain. In fact, it is estimated that there are 12-20 new cases of SCI per million inhabitants per year. Thus the overall prevalence of SCI in Spain is approximately 350 individuals per million inhabitants. ${ }^{1}$ SCI represents a long-term medical condition that produces irreversible physical, psychological and social consequences. Therefore, SCI individuals are forced to continuously adapt to their condition by making adjustments within several specific domains, including mobility, self-care, lifestyle and social relations. ${ }^{2,3}$ Indeed, the psychological impact of SCI is evidenced by the fact that there is a higher incidence of anxiety and depression in affected individuals when compared with the general population. ${ }^{4}$

The use of coping strategies has been identified as an important mechanism by which SCI individuals adjust to their state of chronic disability. 5,6 Notably, SCI-related coping strategies were found to impact psychological variability more than socio-demographic or lesion-related factors. ${ }^{6}$ Nevertheless, methodological limitations, such as the use of generic coping instruments, ${ }^{2}$ have made it difficult to establish the relationship between coping and SCI adaptation. Indeed, commonly used coping assessments are very long, do not adequately reflect the complexity of SCI and are difficult to compare. ${ }^{5}$

For these reasons, the Spinal Cord Lesion-related Coping Strategies Questionnaire (SCL CSQ) $)^{7,8}$ was developed. The SCL CSQ assesses coping based on three distinct subscales: Acceptance (degree of revaluation of life values), Fighting spirit (extent of independent behaviour in spite of the lesion), and Social reliance (tendency to display negative psychological or social dependency). The original SCL CSQ, which was previously described (that is, item generation, factor identification and scale reliability), was found to meet a basic level of reliability and validity. ${ }^{8}$ In addition, it showed improved performance when compared with a general coping measure. ${ }^{9}$

Notably, socio-demographic and injury-related characteristics (for example, age, time since lesion and gender) were considered during development of the SCL CSQ. ${ }^{8}$ Although there was relatively low variability associated with these background characteristics, the

${ }^{1}$ Àrea de Rehabilitació NeuroPsicoSocial, Institut Guttmann, Institut Universitari de Neurorehabilitació adscrit a la Universitat Autònoma de Barcelona, Badalona, Spain; ${ }^{2}$ Universitat Autònoma de Barcelona, Bellaterra (Cerdanyola del Vallès), Spain; ${ }^{3}$ Fundació Institut d'Investigació en Ciències de la Salut Germans Trias i Pujol, Badalona, Spain; ${ }^{4}$ Unidad de Salud Mental, Hospital Universitario San Ignacio, Bogotá, Colombia; ${ }^{5}$ Department of Basic Psychology, Faculty of Psychology, Universitat Autònoma de Barcelona, Bellaterra, Spain and ${ }^{6}$ Department of Psychology, School of Health, Care and Social Welfare, Mälardalen University, Västerås, Sweden

Correspondence: J Saurí, Àrea de Rehabilitació NeuroPsicoSocial, Institut Guttmann, Institut Universitari de Neurorehabilitació adscrit a la Universitat Autònoma de Barcelona, Badalona 08916, Spain.

E-mail: jsauri@guttmann.com

Received 14 May 2013; revised 25 February 2014; accepted 18 March 2014; published online 29 April 2014 
Acceptance subscale was found to increase with time since injury in the short term (6-12 weeks post injury) ${ }^{10}$ and over several years (persons injured $1-4$ years vs $\geqslant 5$ years). ${ }^{7,8}$ In addition, the Social reliance subscale was reduced over time when considering both the short (6-12 weeks post injury) ${ }^{10}$ and long ( $1-4$ years vs $\geqslant 5$ years) perspectives. $^{8}$

Differences with regard to neurological status were less consistent than those observed when considering time since injury. In the developmental study, individuals with functionally complete tetraplegia, who used a wheelchair and displayed impaired function in their upper extremities (tetraplegia: ASIA A, B, C), reported higher levels of Social reliance than those with less neurological deficit. ${ }^{8}$ In the first European cross-national validation study, subjects with complete paraplegia scored significantly higher in the Fighting spirit subscale when compared with individuals with complete tetraplegia. ${ }^{7}$ In addition, subjects with thoracic injuries produced higher scores related to Fighting spirit than those with cervical injuries. ${ }^{7}$ Although the SCL CSQ was developed to assess individuals with traumatic lesions, it also appears to be applicable to cases involving nontraumatic lesions. ${ }^{7,10,11}$

The SCL CSQ has been used to study the relationship between coping and psychological outcomes. ${ }^{5,10,12-14}$ In fact, higher scores in the Acceptance and Fighting spirit subscales indicated better psychological functioning and quality of life (QoL), whereas high scores in Social reliance were linked with psychological distress. These results have highlighted the fact that appropriate psychological support may promote improved long-term QoL and independence in SCI individuals. ${ }^{14}$ In accordance with this notion, Kennedy et al. ${ }^{11}$ suggested that initial stages after injury were associated with the use of strategies that were not typically required for everyday life.

Our clinical experience has suggested that prolonged Social reliance may produce greater feelings of dependency and psychological discomfort, leading individuals with SCI to drift toward poor adaptation. In contrast, Fighting for the best possible conditions and Acceptance can lead to improved adaptation.

Moreover, we believe that a broader concept of disability adaptation should consider social participation, ${ }^{3}$ absence of psychological problems (for example, anxiety and depression) and a good QoL. ${ }^{15}$

\section{Purpose}

There exists a growing need to develop effective functional measures in the field of neurorehabilitation. In the present study, we have produced a Spanish language version of the SCL CSQ and analysed its factorial structure and validity during the measurement of psychosocial adaptation outcomes. According to previous research, we expected that coping strategies related to Acceptance and Fighting spirit would positively predict psychological adaptation, whereas Social reliance would demonstrate both negative (QoL and social participation) and positive (anxiety and depression) relationships.

\section{MATERIALS AND METHODS}

\section{Participants}

A total of 511 subjects with SCI were included in the study. These individuals were living in the community and attended their annual comprehensive follow-up evaluation at the hospital between March 2010 and July 2011. They were between the ages of 17.5 and 87.2 years (mean: 50.6 years $($ s.d. $=14.3)$ ), were fluent in Spanish and had completed the rehabilitation process. Notably, subjects with concomitant brain injury, communication issues or previous psychiatric disorders were excluded. Socio-demographic and lesion-related data are presented in Tables 1 and 2.
Table 1 Descriptive statistics of lesion-related variables, functional independence, anxiety, depression, quality of life, social integration and coping strategies

\begin{tabular}{|c|c|c|c|c|c|c|}
\hline \multirow[t]{2}{*}{ Variables } & \multirow[t]{2}{*}{$n$} & \multicolumn{2}{|c|}{ Range } & \multirow[t]{2}{*}{ Median } & \multirow[t]{2}{*}{ Mean } & \multirow[t]{2}{*}{ s.d. } \\
\hline & & Min. & Max. & & & \\
\hline Age (years) & 511 & 17.50 & 87.26 & 49.36 & 50.66 & 14.37 \\
\hline Age at injury (years) & 511 & 3.22 & 79.42 & 32.94 & 35.21 & 15.16 \\
\hline Time since injury (years) & 511 & 1.40 & 62.47 & 13.87 & 15.44 & 10.00 \\
\hline SCIM II & 511 & 13 & 100 & 73.00 & 67.18 & 22.97 \\
\hline Anxiety & 511 & 0 & 20 & 5.00 & 5.76 & 3.72 \\
\hline Depression & 511 & 0 & 20 & 3.00 & 4.15 & 3.74 \\
\hline Global QoL & 511 & 4 & 20 & 16.00 & 14.00 & 3.70 \\
\hline CIQ total & 511 & 1 & 25 & 16.00 & 15.54 & 5.28 \\
\hline Acceptance & 511 & 1 & 4 & 3.00 & 3.00 & 0.61 \\
\hline Social reliance & 511 & 1 & 4 & 2.66 & 2.62 & 0.74 \\
\hline Fighting spirit & 511 & 1 & 4 & 3.20 & 3.18 & 0.47 \\
\hline
\end{tabular}

Abbreviations: CIQ, Community Integration Questionnaire scores; Global QoL, quality-of-life scores as measured by the WHOQOL-BREF; SCIM II, Spinal Cord Independence Measure II scores.

\section{Design}

A cross-sectional validation study was used.

\section{Materials}

Data regarding socio-demographic and lesion-related variables were collected from the database at Institut Guttmann, a neurorehabilitation hospital located in Barcelona, Spain.

The instruments selected for use in this study represent commonly used tools, which have previously been applied to the SCI population.

\section{Measures}

Spinal Cord Independence Measure (SCIM II). We assessed functional independence using the second version of the SCIM. The SCIM II consists of three main categories: (1) self-care; (2) respiration and sphincter management; and (3) mobility. Each of these areas is subdivided into 18 subitems, which collectively yield a score ranging between 0 and 100. Higher scores indicate greater functional independence. The psychometric properties of this assessment have been reported elsewhere. ${ }^{16}$

Hospital Anxiety and Depression Scale (HADS). The HADS self-assessment questionnaire contains subscales related to anxiety and depression. Each of these subscales is composed of seven items. Answers are given on a four-step Likert scale (0-3), and the individual response values are summed to yield overall scores for anxiety and depression. The psychometric properties of the Spanish version were previously reported. ${ }^{17}$

Global QoL rating. We utilized the short version of the World Health Organization Quality of Life Questionnaire (WHOQoL-BREF) ${ }^{18}$ to obtain a single rating of overall QoL. This item reads 'How would you rate your quality of life?' and is reported based on a five-point response format that ranges from 1 (very poor) to 5 (very good).

Community Integration Questionnaire (CIQ). Social participation was measured using the revised version of the CIQ, which assesses three domains: home competency, social interactions, and productive activities. Both domainspecific and cumulative (ranging from 0 to 25) scores can be calculated, with higher punctuations indicating better community integration. Notably, this measure has been used previously to assess an SCI population. ${ }^{19}$

SCL CSQ. The SCL CSQ was developed for use with individuals with SCI and is comprised of three subscales: (1) Acceptance, which focuses on the lesion and its ramifications as integrated parts of the individual's life (for example, I have been able to see my injury in relation to other things in life); (2) Fighting spirit, which assesses the subject's ability to make the best of life despite the lesion (for example, I always try to manage on my own as much as possible); and (3) Social reliance, which examines the patient's perception of 
Table 2 Coping strategies and comparisons between socio-demographic and lesion-related variables of the sample

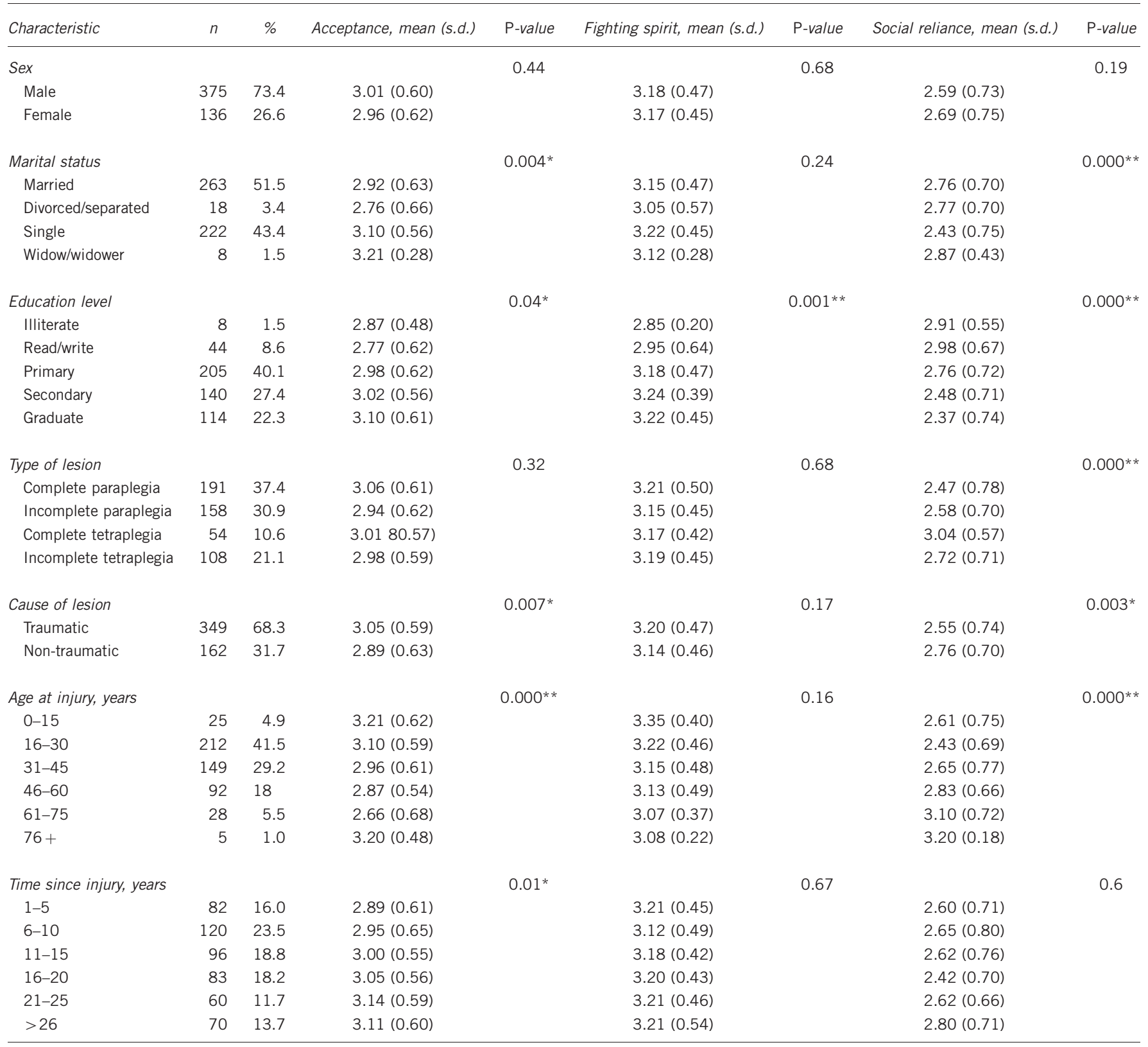

$* P<0.05$.

$* * P<0.001$.

dependence upon others (for example, my injury has taught me that I am now dependent upon others). Items are rated on a four-step Likert scale (1-4). Scores represent the mean of the rating for each subscale, with higher scores indicating greater use of the specific strategy. ${ }^{8}$ Notably, the revised version of the English questionnaire was used for the translation process in this study, ${ }^{10}$ and a protocolled process was followed for obtaining linguistic, conceptual and metric equivalencies. Specifically, items were translated from both English and Swedish into Spanish, which resulted in five versions that were assessed by five expert psychologists. A unified version was produced and evaluated during individual interviews of 10 subjects. These 10 participants indicated that they had difficulties understanding some of the items within the forward-translated questionnaire. Following correction of these discrepancies, two SpanishEnglish bilinguals performed backward translation for comparison to the original version and observed equivalence. Subsequently, individual interviews were conducted on five participants, who indicated good comprehension.
Finally, the SCL CSQ-S was tested in a pilot study in order to confirm that there was a high level of item acceptability and comprehension. Items resulting from the backward translation process to Spanish are shown in the Appendix.

\section{Procedure}

For data collection, a psychologist personally delivered a folder containing the questionnaires and respective instructions to each study participant during his/ her annual examination at the hospital. Notably, the Institut Guttmann Ethics Committee approved the study, and all participants gave written informed consent.

\section{Data analysis}

Several statistical techniques were used in the present study, and we conducted both descriptive and correlational analyses. Indeed, $t$-tests were performed to 
examine possible gender or lesion-related differences, whereas successive oneway analysis of variance tests were used to examine the effect of sociodemographic and lesion-associated variables on coping strategies. Confirmatory factor analysis was also conducted using robust methods and reliability coefficients. In addition, hierarchical regression analysis was performed. In this regard, socio-demographic factors, lesion-related variables and functional independence were entered into the sequential equations, respectively, followed by coping strategies. Furthermore, psychosocial adaptation measures were considered to be dependent variables (that is, anxiety, depression, QoL and social participation). Data were analysed using the Statistical Package for Social Sciences (version 16.0) and EQS 6.1. Moreover, model fit was assumed in accordance with Kline: ${ }^{20}$ a Root Mean Square Error of Approximation $<0.08$ along with Tucker-Lewis Index and Comparative Fit Index values of approximately 0.95 . In order to compare models, the Akaike information criterion was applied, with lower values indicating better fit.

Although there were 10 missing values in the single Global QoL rating, they were replaced using the scale mean and had no impact on our analysis. Notably, there were no other missing data associated with the variables included in the present study.

\section{Statement of ethics}

All applicable institutional and governmental regulations concerning the ethical use of human volunteers were followed throughout the course of this investigation.

\section{RESULTS}

\section{Descriptive statistics}

The study variables are presented in Table 1 . Considering the cutoffs from the anxiety scale, we observed that $378(74.0 \%)$ participants showed non-clinical levels, whereas $70(13.7 \%)$ subjects could be considered as possible cases. However, we found that $63(12.3 \%)$ individuals displayed clinical levels of anxiety. With regard to depression, $415(81.2 \%)$ cases could be classified as non-clinical, 65 (12.7\%) participants represented possible cases and $31(6.1 \%)$ subjects showed clinical levels.

In Table 2, we present the means and s.ds. associated with the different socio-demographic and injury-related variables of the SCL CSQ-S subscales. We found no gender-based differences. Nevertheless, significant differences were observed in the Acceptance subscale with relation to marital status, education level, cause of lesion, age at injury and time since injury. In fact, pairwise comparisons revealed that single, graduate individuals, who suffered a traumatic injury when younger, displayed significantly higher scores for Acceptance. With regard to Fighting spirit, greater scores were associated with individuals having secondary or graduate educational levels. For the Social reliance subscale, pairwise comparisons indicated that higher scores were associated with married individuals having lower educational levels, who had suffered tetraplegia caused by non-traumatic aetiology at a late age.

\section{Confirmatory factor analysis}

Our findings indicated that the original correlated, three-factor model sufficiently fit the data obtained in this study (Table 3). Indeed, items were found to be good indicators of their respective latent factors, showing adequate factorial charge ranges: Acceptance (0.57-0.73), Fighting spirit (0.41-0.72), and Social reliance (0.68-0.75) (see Figure 1). In addition, the following correlations were calculated among the latent factors: Acceptance with Fighting spirit (0.89; $P<0.05)$, Acceptance with Social reliance $(-0.26 ; P<0.05)$, and Fighting spirit with Social reliance $(-0.17 ; P<0.05)$. Considering the high correlation observed between Acceptance and Fighting spirit, alternative models were tested, involving items from the two factors that pertained to a unique factor or two factors combined into a second-order factor. We found that the original three-factor model, which displayed better performance within all fit indices, was the most plausible option (see Table 3).

Furthermore, we calculated the reliability coefficient (Cronbach's $\alpha$ ) for each subscale: Acceptance (0.74), Social reliance (0.76), and Fighting spirit (0.69). Indeed, these coefficients approximated the value for acceptable internal consistency (0.70).

\section{Correlation analysis}

Bivariate Pearson's correlation coefficients were calculated. Although age and age at time of injury correlated moderately with other sociodemographic and lesion-related variables, they showed lower correlation with adaptation and coping measures. Moreover, our data indicated that anxiety $(r=-0.35)$, depression $(r=-0.49)$, Acceptance $(r=0.48)$ and Fighting spirit $(\mathrm{r}=0.37)$ correlated moderately with QoL. The correlation matrix for all study variables is presented in Table 4. We observed that the correlation between Acceptance and Fighting spirit was considerably lower in bivariate analyses compared with confirmatory factor analysis. This finding may result from the fact that confirmatory factor analysis correlation terms are obtained between measures without measurement error.

\section{Regression analysis}

Results obtained from the multiple hierarchical regression analysis are shown in Table 5. When global QoL rating was considered as the dependent variable, lesion-related and socio-demographic factors did not significantly contribute to the variance. Our analysis revealed that cause of injury and Acceptance accounted for $29.2 \%$ of the variance. Also, traumatic injury and higher Acceptance scores were related to increased QoL.

When CIQ was the dependent variable, actual age, marital status, gender, education, SCIM, Acceptance, Fighting spirit and Social reliance accounted for $58.1 \%$ of the variance. In addition, we found that male gender, younger age and scoring high in positive coping skills were associated with greater CIQ scores.

Table 3 Fit of CFA models

\begin{tabular}{|c|c|c|c|c|c|c|}
\hline & $X^{2}(d f)$ & $x^{2} / d f$ & $\mathrm{CFI}$ & $T L I$ & RMSEA $(90 \% \mathrm{Cl})$ & $A / C$ \\
\hline M2: alternative model & $176.03(53)^{* *}$ & 3.32 & 0.92 & 0.92 & $0.67(0.56-0.78)$ & 70.03 \\
\hline
\end{tabular}

Abbreviations: AKI, Akaike information criterion; CFA, confirmatory factor analysis; CFI, Comparative Fit Index; Cl, confidence interval; RMSEA, Root Mean Square Error of Approximation; TLI, Tucker-Lewis Index.

Note: M1: the three original factors are intercorrelated; M2: the items of the two correlated factors, Acceptance and Fighting spirit, are tested as pertaining to an unique factor; M3: the two Note: M1: the three original factors are intercorrelated; M2: the items of the two correlated factors,
correlated factors, Acceptance and Fighting spirit, are tested as conforming a second-order factor. $* * P<0.001$ 


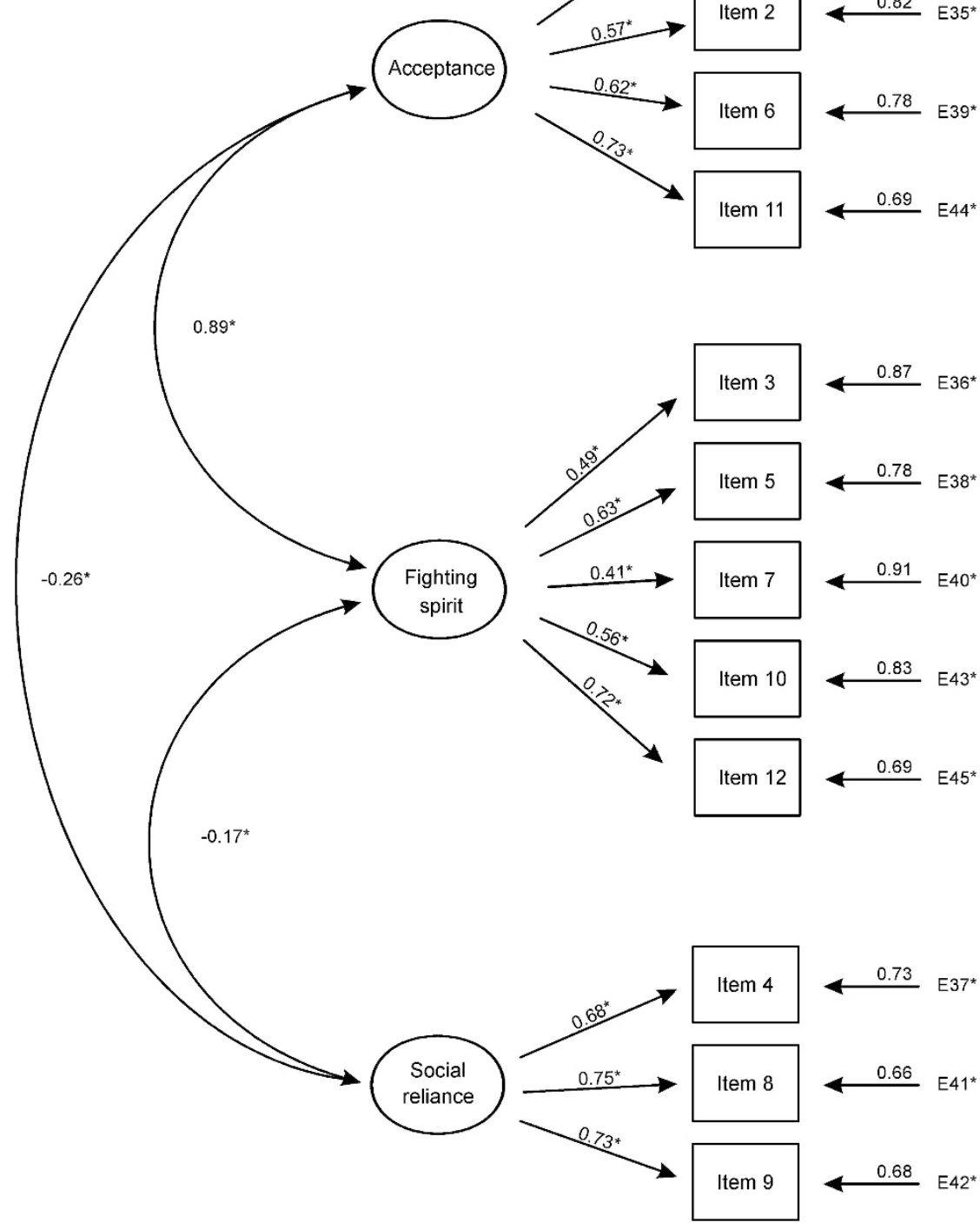

Figure 1 Parameter estimations for structural equation model of the SCL-CSQ-S. ${ }^{*} P<0.05$.

In the case of anxiety as the dependent variable, gender, education, marital status, Acceptance and Social reliance accounted for a $21.9 \%$ of the variance. Furthermore, female gender, low educational level, single relationship status and scoring high in Social reliance were found to be predictors of increased anxiety scores. In this regard, Acceptance was demonstrated to be a protective coping skill.

Our analysis of depression indicated that Acceptance, Fighting spirit and Social reliance could account for $35.4 \%$ of the variance. High positive coping scores were found to predict lower depression scores, and Social reliance appeared to represent a negative coping strategy.

Standardized regression coefficients from the three models indicated that Acceptance and Fighting spirit were positively related to adaptation outcomes. In addition, Acceptance was negatively related to anxiety and depression, whereas Fighting spirit was only negatively associated with depression. In contrast, Social reliance was negatively related with CIQ and positively associated with anxiety and depression. Taken together, our findings suggest that these three distinct coping strategies have differential effects over adaptation outcomes, supporting the notion that Acceptance and Fighting spirit represent independent factors.

\section{DISCUSSION}

In the present study, we present evidence that cultural and linguistic equivalence was obtained following translation of the original SCL CSQ to the Spanish language. Moreover, our findings support the original factorial structure of the scale, as we observed internal consistency and adaptation outcomes that were similar to those described in previous studies. ${ }^{7,8,10}$ However, the less than optimal internal consistency shown by this instrument could be attributed to the short length of its subscales. Nevertheless, our results confirm that the structure of this tool is robust, as data obtained using the SCL CSQ-S largely replicated the original theoretical framework. Although fit indices were acceptable, the correlation observed between 
Table 4 Correlations among the study variables

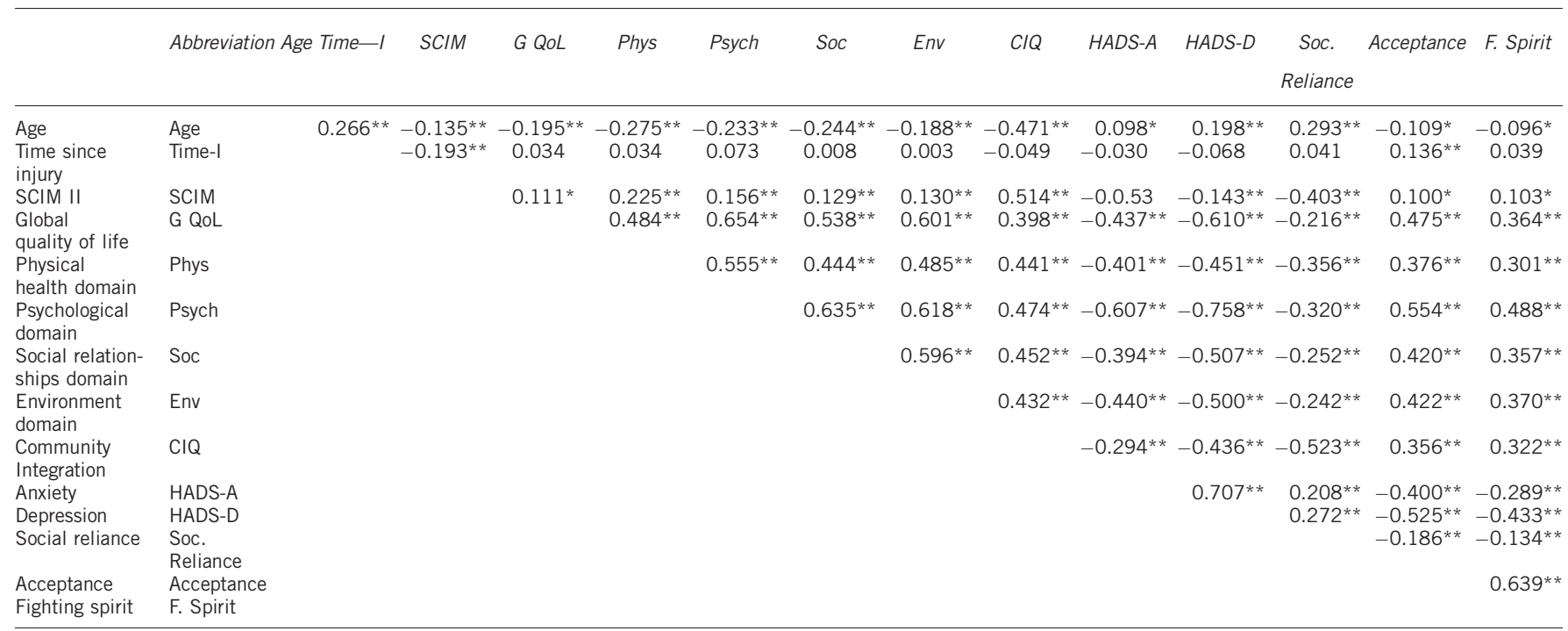

Abbreviations: Acceptance, SCL-CSQ-R Acceptance; CIQ, Community Integration Questionnaire; Env, WHOQOL-BREF Environment domain; F. Spirit, SCL-CSQ-S Fighting Spirit; G QoL, WHOQOLBREF Global Quality of Life rating; HADS-A, Hospital Anxiety and Depression Scale-anxiety symptom; HADS-D, Hospital Anxiety and Depression Scale-depression symptom; Phys, WHOQOLBREF Physical domain; Psych, WHOQOL-BREF Psychological domain; Soc. Reliance, SCL-CSQ-S Social reliance; Soc, WHOQOL-BREF Social relationships domain.

Note: * correlations are significant at $\alpha<0.05$ level.

${ }^{* *}$ Correlations are significant at $\alpha<0.01$ level.

Table 5 Results of the hierarchical regression analyses

\begin{tabular}{|c|c|c|c|c|c|}
\hline Dependent variable & $\mathrm{R}^{2}$ & Predictor variables & $\beta$ & $\mathrm{t}$-value & P-value \\
\hline \multirow[t]{2}{*}{ Global QoL } & 0.292 & Cause of lesion & -0.130 & -2.710 & 0.007 \\
\hline & & Acceptance & 0.370 & 6.620 & $<0.001$ \\
\hline \multirow{5}{*}{$C I Q$} & & Marital status & 0.075 & 2.175 & 0.030 \\
\hline & & Actual age & -0.226 & -0.974 & $<0.001$ \\
\hline & & Educational level & 0.123 & 3.842 & $<0.001$ \\
\hline & & Acceptance & 0.151 & 3.935 & $<0.001$ \\
\hline & & Fighting spirit & 0.117 & 2.979 & 0.003 \\
\hline \multirow[t]{4}{*}{ HADS Anxiety } & 0.219 & Gender & 0.146 & 3.530 & $<0.001$ \\
\hline & & Marital status & -0.098 & -2.053 & 0.041 \\
\hline & & Educational level & -0.089 & -2.029 & 0.043 \\
\hline & & Social reliance & 0.117 & 2.508 & 0.011 \\
\hline
\end{tabular}

Abbreviations: CIQ, Community Integration Questionnaire; Global QoL, WHOQOL-BREF Global quality-of-life rating; HADS-A, Hospital Anxiety and Depression Scale-anxiety symptom; HADS-D, Hospital Anxiety and Depression Scale-depression symptom.

Note: Only significant effects are shown.

Acceptance and Fighting spirit was high. Thus, an overlap between these coping strategies could be hypothesized. Indeed, it is possible that SCI individuals accept the consequences of their disability (Acceptance) through achieving goals (Fighting spirit). Although future investigations will be needed to verify the possible connection between these coping mechanisms, the three-factor form of the scale allowed us to predict the impact of coping strategies on psychosocial adaptation outcomes.

Our findings have suggested the existence of two well-differenced patterns of coping. Well-educated individuals, who suffered a traumatic injury when they were young, were able to effectively utilize
Acceptance as a coping strategy. On the other hand, Social reliance represented the main coping mechanism used by married individuals with a low education level, who displayed a non-traumatic aetiology. Therefore, in view of these results, it is feasible that people with higher educational levels can visualize themselves in occupational roles that are more dependent on their cognitive abilities, which are not impaired, whereas those with lower educational levels often perform physically demanding jobs that require abilities that they no longer possess following injury (for example, cleaner, waitress, workman).

Our findings also confirm previous data suggesting that injury characteristics do not constitute the main predictors of psychosocial 
adaptation. ${ }^{2,6}$ In the past studies, adjustment was described as the absence of anxiety and depression. Here we rely on a model that centres on a broader definition of psychosocial adaptation, taking into account not only the absence of disorders but also the positive indicators (for example, QoL and community integration). ${ }^{15}$ Furthermore, the results of the present study suggest that functional and injury characteristics do not represent decisive factors in the adaptation process to disability. In contrast, coping mechanisms appear to be related to adaptation, especially the strategy of Acceptance. However, we observed that traumatic injuries tended to yield better results when considering global QoL. This might be explained by the fact that non-traumatic lesions, which possibly result from medical processes (for example, tumours, degenerative conditions, and vascular problems), could be associated with a longer adjustment process than traumatic type injuries (that is, individuals with SCI may be able to accept the prognosis more quickly in the case of an accident). In this regard, future research should focus on trying to identify the role that aetiology has in the adaptation to disability.

According to Lazarus and Folkman, ${ }^{21}$ individuals are more likely to engage in Acceptance and active coping strategies when they perceive a stressful situation as treatable/manageable and estimate the degree to which they have the skills and/or resources to cope with their situation. Thus, those who accept the situation might be more likely to gain psychological well-being, thereby facilitating social integration into the community. As in previous reports, ${ }^{12-14}$ Acceptance in this study seemed to be beneficial with regard to psychosocial factors and promoted adaptive changes. Indeed, Elfström et al. ${ }^{12}$ found that Acceptance displayed standardized $\beta$ coefficients of 0.38 for general QoL, 0.40 for social functioning and -0.37 for depression. Therefore, when compared with Fighting spirit and Social reliance, Acceptance seemed to be the most powerful coping strategy with regard to adaptation outcomes. ${ }^{13}$ Social reliance was associated with increased levels of psychological distress in the present study. Likewise, Elfström et al. ${ }^{12}$ found that Social reliance contributed to depression $(\beta=0.12)$ and, in an inverse manner, social functioning $(\beta=-0.21)$. Therefore, they suggested that the use of Social reliance could involve externalization of the perception of control over the situation. Additionally, Kennedy et al. ${ }^{10}$ found that Acceptance $(\beta=-0.22)$ and Fighting spirit $(\beta=-0.12)$ could predict depression, whereas Social reliance was linked to anxiety $(\beta=0.18)$ and depression $(\beta=0.20)$.

In accordance with previous studies, ${ }^{10,12-14}$ Acceptance and Fighting spirit coping strategies appeared to predict adaptation to disability in our study, ultimately protecting the individual from anxiety and depression. Also, in line with our hypothesis, the Social reliance coping mechanism was negatively related to community integration but positively associated with anxiety and depression. As shown in previous investigations, Social reliance was significantly related to lower functional outcomes and difficulties during social interactions. ${ }^{11,14}$

Our descriptive analysis revealed that our sample was similar to other previously examined cohorts as well as to the general SCI population. However, the participants in the present study displayed an increased mean age in comparison to other investigations. ${ }^{5}$ This might be explained by the fact that most SCI studies have focused on traumatic injuries, which tend to occur at younger ages, whereas in the present study we have included non-traumatic injuries, which tend to occur at older ages. However, a recent study has described a trend toward increased traumatic aetiologies among the elderly in the Spanish population. ${ }^{22}$
Here, normal levels of anxiety and depression were observed, and QoL scores were similar to those described by previous studies. ${ }^{10}$ Therefore, our sample appeared to be psychologically well adjusted, with a low proportion of individuals showing clinical levels of anxiety and depression (approximately 12\% and 6\%, respectively).

The current work was subject to several limitations. Indeed, the findings of this study should be interpreted with caution owing to the sampling strategy (that is, follow-up assessment) and the crosssectional design. For this reason, we found it difficult to generalize our results to other SCI populations and determine causality. Although the SCL CSQ performed psychometrically well when utilized for patients 6 weeks post injury, ${ }^{10}$ further research will be needed to test the efficacy of the scale when used during the early stages following injury. Furthermore, the high correlation that we observed between the Acceptance and Fighting spirit coping strategies in Spanish SCI individuals will need to be corroborated by further investigation.

In summary, this study supports the use of the SCL CSQ-S as a tool to measure the use of coping strategies in Spanish SCI individuals. Indeed, knowledge obtained from this scale can be utilized for both research and clinical work. Our study has contributed to the overall goal of adapting measurement instruments to local language and culture in order to facilitate the use of these important tools in diverse clinical settings. Furthermore, the results of the present study have provided further support for the positive effect of psychological factors (for example, coping strategies) during adaptation to physical disabilities.

Although the SCL CSQ previously demonstrated acceptable psychometric properties, only a few studies have analysed its sensitivity to change. ${ }^{11,14}$ Therefore, future research should focus on addressing this topic with regard to the SCI population as well as improving psychological interventions (for example, coping effectiveness training). ${ }^{11}$ Moreover, further research will be needed to evaluate the psychometric properties of the SCL CSQ-S in other Spanishspeaking populations in order to evaluate transcultural validation of the questionnaire.

\section{DATA ARCHIVING}

There were no data to deposit.

\section{CONFLICT OF INTEREST}

The authors declare no conflict of interest.

\section{ACKNOWLEDGEMENTS}

This work was partially supported by funding from the ADECCO foundation and Agilent in the setting of the studies of the Qvidlab in the Institut Guttmann. We appreciate and thank all the individuals with SCI who participated in the study. Thanks to Jordi Vilaseca, Monica Miriam Ondategui, Wendy Armengol, Karen Frantz and Mark Frantz for their help in the translation process. We want to give a special mention to Lluïsa Curcoll, Alicia Nuñez, Mariona Gifre, Angel Gil, Eloy Opisso and the other members of the staff of the NeuroPsychoSocial Rehabilitation Area of the Institut Guttmann who gave their time to help with the recruitment and questionnaire process.

1 Mazaira J, LaBanda F, Romero J, García M, Gambarrutta C, Sánchez A et al. Epidemiología de la lesión medular y otros aspectos. [Spinal Cord Injury epidemiology and other aspects]. Rehabilitación 1998; 32: 365-72.

2 Galvin LR, Godfrey HP. The impact of coping on emotional adjustment to spinal cord injury (SCl): review of the literature and application of a stress appraisal and coping formulation. Spinal Cord 2001; 39: 615-627. 
3 Kennedy P, Lude P, Taylor N. Quality of life, social participation, appraisals and coping post spinal cord injury: a review of four community samples. Spinal Cord 2006 02; 44: 95-105.

4 Craig A, Tran Y, Middleton J. Psychological morbidity and spinal cord injury: a systematic review. Spinal Cord 2009; 47: 108-114.

5 Kennedy P, Evans M, Sandhu N. Psychological adjustment to spinal cord injury: the contribution of coping, hope and cognitive appraisals. Psychol Health Med 2009; 14: 17-33.

6 Kennedy P, Marsh N, Lowe R, Grey N, Short E, Rogers B. A longitudinal analysis of psychological impact and coping strategies following spinal cord injury. Br J Health Psychol 2000; 5: 157-172.

7 Elfström ML, Kennedy P, Lude P, Taylor N. Condition-related coping strategies in persons with spinal cord lesion: a cross-national validation of the Spinal Cord Lesionrelated Coping Strategies Questionnaire in four community samples. Spinal Cord 2007; 45: 420-428.

8 Elfström ML, Rydén A, Kreuter M, Persson L, Sullivan M. Linkages between coping and psychological outcome in the spinal cord lesioned: development of SCL-related measures. Spinal Cord 2002; 40: 23-29.

9 Elfström ML, Kreuter M, Persson L, Sullivan M. General and condition-specific measures of coping strategies in persons with spinal cord lesion. Psychol Health Med 2005; 10: 231-242.

10 Kennedy P, Lude P, Elfström M, Smithson E. Cognitive appraisals, coping and quality of life outcomes: a multi-centre study of spinal cord injury rehabilitation. Spinal Cord 2010; 48: 762-769.

11 Kennedy P, Lude P, Elfström ML, Smithson E. Appraisals, coping and adjustment pre and post SCI rehabilitation: a 2-year follow-up study. Spinal Cord 2012; 50: 112-118.

12 Elfström M, Rydén A, Kreuter M, Taft C, Sullivan M. Relations between coping strategies and health-related quality of life in patients with spinal cord lesion. J Rehabil Med 2005; 37: 9-16.

\section{APPENDIX}

Items in Spanish from each coping factor:

\section{Acceptance}

He sido capaz de ver mi lesión como un aspecto más de la vida.

Mi lesión me ha hecho aprender a apreciar aspectos de la vida que no valoraba anteriormente.

Creo que he aceptado mi lesión.

Lo que he perdido físicamente lo he ganado en muchos otros aspectos.

Fighting spirit

Es importante para mí marcarme objetivos por los que pueda luchar para conseguir.
13 Elfström ML, Kreuter M, Rydén A, Persson L, Sullivan M. Effects of coping on psychological outcome when controlling for background variables: a study of traumatically spinal cord lesioned persons. Spinal Cord 2002; 40: 408-415.

14 Kennedy P, Lude P, Elfström ML, Smithson EF. Psychological contributions to functional independence: a longitudinal investigation of spinal cord injury rehabilitation. Arch Phys Med Rehabil 2011; 92: 597-602.

15 Martz E, Livneh H, Priebe M, Wuermser LA, Ottomanelli L. Predictors of psychosocial adaptation among people with spinal cord injury or disorder. Arch Phys Med Rehabil 2005; 86: 1182-1192.

16 Catz A, Itzkovich M, Steinberg F, Philo O, Ring H, Ronen J et al. The Catz-Itzkovich SCIM: a revised version of the Spinal Cord Independence Measure. Disabil Rehab 2001; 23: 263-268.

17 Quintana JM, Padierna A, Esteban C, Arostegui I, Bilbao A, Ruiz I. Evaluation of the psychometric characteristics of the Spanish version of the Hospital Anxiety and Depression Scale. Acta Psychiatr Scand 2003; 107: 216-221.

18 Jang Y, Hsieh C, Wang Y, Wu Y. A validity study of the WHOQOL-BREF assessment in persons with traumatic spinal cord injury. Arch Phys Med Rehab 2004; 85: 1890-1895.

19 High AT, Braden AL, Craggs JG, Jensen MP. Psychometric properties of the community integration questionnaire in an heterogeneus sample of adults with psychical disability. Arch Phys Med Rehabil 2011; 92: 1602-10.

20 Kline RB. Principles and Practices of Structural Equation Modeling, 3rd edn. The Guilford Press: New York, NY, USA, (2010).

21 Lazarus RS, Folkman S. Stress, Appraisal and Coping. Springer: New York, NY, USA, 1984.

22 Van Den Berg M, Castellote JM, Mahillo-Fernandez I, de Pedro-Cuesta J. Incidence of traumatic spinal cord injury in Aragón, Spain (1972-2008). J Neurotrauma 2011; 28: 469-77.

A pesar de mi lesión hago todo lo que puedo en la vida para estar lo mejor posible.

No acepto que mi lesión gobierne mi vida.

Intento arreglármelas solo siempre que puedo.

Siempre busco nuevas maneras para hacerme la vida más fácil.

Social reliance

Ahora debo depositar mi confianza en los demás para que me ayuden.

Me sentiría completamente indefenso sin el apoyo de los demás.

Mi lesión me ha enseñado que ahora soy dependiente de los otros. 